\title{
CHARACTERIZATION OF LANGMUIR AND LANGMUIR-BLODGETT FILMS OF AN OCTASUBSTITUTED ZINC PHTHALOCYANINE
}

\author{
J. Torrent-Burgués ${ }^{\text {a,d,* }}$, P. Cea ${ }^{\text {b,c }}$, I. Giner $^{b}$, E. Guaus ${ }^{\text {a }}$
}

a Department of Chemical Engineering, Universitat Politècnica de Catalunya (UPC), C/ Colom 1, 08222 Terrassa (Barcelona), Spain

b Departamento de Química Orgánica y Química Física, Facultad de Ciencias, Universidad de Zaragoza, 50009, Spain.

c Instituto de Nanociencia de Aragón (INA) y Laboratorio de Microscopias Avanzadas (LMA), Edificio i+d. Campus Rio Ebro, Universidad de Zaragoza, C/Mariano Esquillor, s/n, 50017 Zaragoza, Spain.

d Institut de Bioenginyeria de Catalunya (IBEC), 08028 Barcelona, Spain

*Corresponding author 


\section{Abstract}

In this work we report the fabrication of Langmuir and Langmuir-Blodgett (LB) films of a substituted ZnPc (octakis(oxyoctyl)phthalocyanine of zinc), and their characterization by means of several techniques. These characterization techniques include surface pressure $(\pi-A)$ and surface potential $(\Delta V-A)$ isotherms as well as $U V$-Vis Reflection spectroscopy and Brewster Angle Microscopy (BAM) for the films at the air-water interface together with UV-Vis absorption and IR spectroscopies and Atomic Force Microscopy (AFM) for the LB films. The $\pi-A$ and $\Delta V$-A isotherms and BAM images indicate a phase transition at a surface pressure of ca. $9 \mathrm{mN} / \mathrm{m}$ and a multilayer formation at surface pressures around $19-20 \mathrm{mN} / \mathrm{m}$; at a surface pressure around $27 \mathrm{mN} / \mathrm{m}$ a disordered collapse of the film occurs. In addition, AFM images of LB films at $\pi=10 \mathrm{mN} / \mathrm{m}$ and $\pi=20 \mathrm{mN} / \mathrm{m}$ show a monomolecular and a multilayered film, respectively. The comparison of the UV-Vis spectrum of $\mathrm{ZnPc}$ in solution, the reflection spectra of the Langmuir films and UV-Vis spectra of LB films reveals a significant reduction in the Q band intensity for the films, indicative of an organization of ZnPc in the Langmuir and LB films versus the random distribution in solution. The UV-Vis reflection spectra are also consistent with multilayer formation at surface pressures around $19-20 \mathrm{mN} / \mathrm{m}$. The relative intensities of the IR spectrum bands change from the $\mathrm{KBr}$ pellet to the $\mathrm{LB}$ film which is also attributable to orientation effects in the film. Cyclic voltammetic experiments of LB films incorporating the ZnPc derivative show peaks that can be correlated with redox processes occurring in the phthalocyanine ring. A small but significant influence of the surface pressure and the number of deposited layers in the electrochemical behaviour is observed. The electrochemical response of cast films exhibits some differences with respect to that of LB films which have been attributed to their different molecular organization. 


\section{Keywords}

Zinc phthalocyanine, spectroscopic techniques, AFM, organized thin films, Langmuir-Blodgett, multilayer formation, electrochemistry. 


\section{Introduction}

Phthalocyanines (Pc) and metallo-phthalocyanines (MPc) have been intensively used for many years as blue and green dyes, but recently they have also been investigated for their applications as catalysts, chemical sensors, photosensitizers, photoconductors, in organic electronic devices, organic solar cells and photonic and optoelectronic technologies [1-7]. These applications usually require a thin film deposited on a solid substrate, but one of the characteristics of these compounds is their strong aggregation which hinders the fabrication of homogeneous films. The Langmuir-Blodgett (LB) technique is a sophisticated method that offers the way to obtain well-ordered mono and multilayered films, and a wide range of surface characterization techniques can be used to study the structure of such films. Studies of LB films incorporating MPc are important in the understanding of interfacial spectroscopic processes occurring in organic solid materials deposited on inorganic solid substrates, which will result in further developing of photovoltaic and optoelectronic devices. The crucial points in searching for good quality of optoelectronic and photonic devices are effective electron transfer processes in dye layers as well as proper molecular arrangements at the interface of dye layer-solid substrate. Some properties have been reported to depend on the arrangement of molecules in the films [8]; thus, for example, the photovoltaic effects are varied by changes in molecular orientation. In addition, the fabrication of Pc ultrathin films via the LB technique may be advantageous from a technological point of view, since parameters such as film architecture and organization can be achieved without post-thermal treatments [9].

In particular, zinc phthalocyanines $(\mathrm{ZnPc})$ have received less attention but recent investigations of these compounds, or other dyes, target on applications in photodynamic therapy of cancer [10-13], or as promising materials for organic solar cells [7]. Thus, only a few works have focused in thin films of ZnPc [7, 8, 14-18]; Schunemann et al. [7], Peisert et al. [8] 
and Schöllhorn et al. [14, 15] investigated films obtained by vapour deposition, Ozoemena et al. [16] studied self-assembled monolayers, Yoshimoto et al. [17] used adlayers in their studies and Chowdhury et al. [18] obtained thin films of ZnPc by vapour deposition and a subsequent annealing process. The LB technique for the assembly of $\mathrm{ZnPc}$ has been used in a limited number of works [1, 9, 19-23], and recently Qiu et al. [24] used the horizontal transfer technique (Langmuir-Schaefer, LS).

O’Flaherty et al. [1] reported that tetra-t-butylPcZn molecules arranged in Langmuir films form arrays of side-by-side lying cofacially aggregated cylindrical rodlike entities, at high surface pressures. In addition, it was demonstrated that the phase change from a low-density state with flat-lying molecules to a high-density state with edge-on surface arrangement was induced by lateral compression. Gaffo et al. [9] demonstrated by IR spectroscopical methods that 31-layer LB films incorporating either ZnPc or $\mathrm{F}_{16} \mathrm{ZnPc}$ show no molecular order at least in the direction perpendicular to the substrate surface. Therefore, the order that was observed in the X-ray diffractograms indicates that the molecules might be organized in crystallites that are randomly oriented in the film. Osburn et al. [19] studied several octasubstituted phthalocyanines and reported that the octa-ether derivatives showed the least tendency towards aggregation and that cast and LB films showed a tendency towards the formation of columnar aggregates, evidenced by the blue shift of the Q-band in the absorbance spectrum. Fully compressed films show the Pc rings tilted by $50-60^{\circ}$. Fouriaux et al. [20] studied the influence of the metal, including Zn, on LB films of tetraamidometalloPc, and they concluded that Co and Zn Pc are coordinated with water and therefore oriented with an angle of $60^{\circ}$ with respect to the normal to the air-water interface or to the substrate; NiPc is not coordinated with water, while $\pi-\pi$ interactions become possible and the molecules can orient more vertically; and CuPc is an intermediate case. Cook et al. [21] reported the presence of domains in LB multilayers of octan-alkoxy Pc in which the molecules are arranged with their planes approximately perpendicular 
to the substrate surface. Souto et al. [22] in their study of two sulphonated ZnPc derivatives concluded that both the surface behaviour of the Langmuir monolayers and the structure of the LB film depend on the nature of the substituents. Thus, the LB film IR spectrum for one of the sulphonated compounds reflected a preferential organization of the molecules with the macrocycle plane perpendicular to the solid substrate, whereas the IR spectrum of the other derivative corresponds to the spectrum of a dispersion of the material in a $\mathrm{KBr}$ pellet. Kimura et al. [23] studied low-symmetry MPc and found different molecular orientations depending on the MPc. Qiu et al. [24] studied films of a ZnPc fabricated by using the LS technique and investigated the chiral character of ZnPc films incorporating achiral molecules. They found that mixed J-, M- and H-aggregates were formed, and suggested that the molecular arrangement in a helical manner is responsible for the optical activity in the films. Recently, Chen et al. [25] have pointed out that low aggregation in $\mathrm{ZnPc}$ is important since aggregation causes a drastic decay of optical properties. Consequently, further investigation on ZnPc films is necessary.

In this work we report the formation of Langmuir and LB films of a substituted ZnPc (octakis(oxyoctyl)phthalocyanine of zinc, Figure 1), here oxyZnPc, and their characterization by means of several techniques including surface pressure $(\pi-A)$ and surface potential $(\Delta V-A)$ isotherms as well as UV-Vis Reflection spectroscopy and Brewster Angle Microscopy (BAM) for the films at the air-water interface together with UV-Vis absorption and IR spectroscopies, Atomic Force Microscopy (AFM) for the LB films. The electrochemical behaviour of oxyZnPc LB films is also reported in this contribution. Qiu et al. [24] reported the fabrication and optical characterization of LS films incorporating oxyZnPc. The present contribution represents a complementary work on the same material in which BAM images and UV-Vis spectra of Langmuir films of oxyZnPc are presented. In addition, the Langmuir films have been transferred by the LB method and the AFM images of these films are presented together with a detailed study of the electrochemical behaviour of oxyZnPc LB films. In particular, the 
objective of this contribution is to study the fabrication and the characterization of well-ordered mono and multilayered LB films incorporating zinc phthalocyanines for their subsequent use as efficient photosensitizers, in photodynamic therapy or in photovoltaics. With this aim the electrochemistry of LB films of oxyZnPc deposited on a glassy carbon electrode in aqueous medium has been determined and the results have been interpreted in terms of the molecular organization of the material in the LB films.

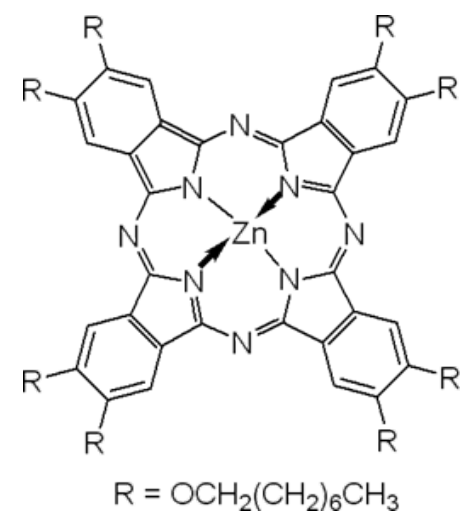

Figure 1. Chemical structure of Zinc 2,3,9,10,16,17,23,24-octakis(octyloxy)-29H,31Hphthalocyanine, abbreviated as oxyZnPc in this contribution.

\section{Experimental Section}

The films were prepared on a Nima Teflon trough with dimensions $720 \times 100 \mathrm{~mm}^{2}$, which was housed in a constant temperature $\left(20 \pm 1^{\circ} \mathrm{C}\right)$ clean room. The surface pressure $(\pi)$ of the monolayers was measured by a Wilhelmy paper plate pressure sensor. The subphase was ultrapure water (Milli-Q ${ }^{\circledR}$, resistivity $18.2 \mathrm{M} \Omega \cdot \mathrm{cm}$ ). A $5 \cdot 10^{-5} \quad \mathrm{M}$ solution of octakis(oxyoctyl)phthalocyanine of zinc (Figure 1, supplied by Sigma-Aldrich) in chloroform (HPLC grade, 99.9\%, purchased from Aldrich and used as received) was delivered from a syringe held very close to the surface allowing the surface pressure to return to a value as close 
as possible to zero between each addition. The solvent was allowed to completely evaporate over a period of at least 15 minutes before compression of the monolayer commenced at a constant sweeping speed in-between 1.3 and $1.8 \AA^{2} /$ (molecule-minute). Each compression isotherm was recorded at least three times to ensure the reproducibility of results, even though it is well known that certain variability may occur due to the influence of several factors [19]. Surface potential vs. area per molecule, $\Delta V$-A, isotherms were recorded using a Kelvin Probe provided by Nanofilm Technologie GmbH, Göttingen, Germany. A UV-Vis reflection spectrophotometer from Nanofilm Technologie, whose details can be found elsewhere [26], was used to obtain the reflection spectra of the Langmuir films during the compression process. BAM images were obtained with a microBAM model (NIMA-Nanofilm), which has a lateral resolution of ca. $8 \mu \mathrm{m}$.

The solid substrates used for the transferences (quartz and ZnSe, for the ultraviolet and infrared measurements, respectively) were cleaned carefully as described elsewhere [27, 28]. In addition, freshly cleaved Highly Ordered Pyrolytic Graphite (HOPG) was used for AFM characterization. The monolayers were deposited at a constant surface pressure by the vertical dipping method and the dipping speed was $6 \mathrm{~mm} / \mathrm{min}$. Quartz Crystal Microbalance (QCM) measurements were carried out using a Stanford Research System instrument and employing AT-cut, $\alpha$-quartz crystals with a resonant frequency of $5 \mathrm{MHz}$ having circular gold electrodes patterned on both sides. UV-Vis spectra of the LB films were acquired on a Varian Cary 50 spectrophotometer, and recorded using a normal incident angle with respect to the film plane. The infrared spectra of the $\mathrm{LB}$ films or $\mathrm{KBr}$ pellets were obtained with a Jasco 410 spectrophotometer. The LB films spectra were recorded using a normal incident angle with respect to the film plane. AFM images were acquired with a Multimode atomic force microscope attached to a Nanoscope IV controller (Digital Instruments, Santa Barbara, CA) operating at ambient atmosphere. The microscope was placed on a $\mathrm{N}_{2}$-operated vibration 
isolation table. Topographic images were acquired in tapping mode using Si tips with a nominal vertical spring constant of $40 \mathrm{~N} / \mathrm{m}$. All the images were recorded at room temperature.

Reagents and solvents used for cyclic voltammetry experiments were of high quality: analytical grade sodium perchlorate $\left(\mathrm{NaClO}_{4}\right.$, from Panreac) and ultra-pure water. Glassy carbon electrodes (GCEs) in sheet, from Goodfellow, were used as working electrodes after their modification with the LB films. In addition, GCEs in rod, from Methrom, were used as working electrodes after their modification with cast films. Cast films were obtained by depositing a drop of oxyZnPc solution on the electrode allowing the evaporation of the solvent. The voltammetric measurements were performed in a conventional three-electrode cell by using a microcomputer-controlled AUTOLAB PSTAT 20 potentiostat/galvanostat implemented with a low current module from Eco Chemie. The reference electrode was an Ag/AgCl/1 $\mathrm{M} \mathrm{NaCl}$ electrode mounted in a Luggin capillary containing a $0.1 \mathrm{M} \mathrm{NaClO}_{4}$ aqueous solution with the same concentration that the one in the electrochemical cell. All potentials refer to this electrode. The counter electrode was a platinum spiral. Before the experiments the solutions were thoroughly de-aerated with Argon. Voltammetric experiments were carried out at a scan rate of $50 \mathrm{mV} / \mathrm{s}$ and at $21^{\circ} \mathrm{C}$.

\section{Results and discussion}

\subsection{Langmuir films}

The compound oxyZnPc has a molecular structure with a highly conjugated $\pi$-electron system. In a manner entirely analogous to other amphiphilic molecules containing aromatic cores, oxyZnPc has a large tendency to aggregate due to strong $\pi-\pi$ interactions. Thus, the BeerLambert law is only followed at relatively low concentrations, at least until $5 \cdot 10^{-5} \mathrm{M}$. Consequently, very dilute solutions $\left(5 \cdot 10^{-5} \mathrm{M}\right)$ are required to fabricate true monolayers at the 
air-water interface. The reproducible surface pressure, $\pi-A$, and normalized surface potential, $\Delta V_{n}-A\left(\Delta V_{n}=\Delta V \cdot A\right)$, isotherms of oxyZnPc are shown in Figure 2.

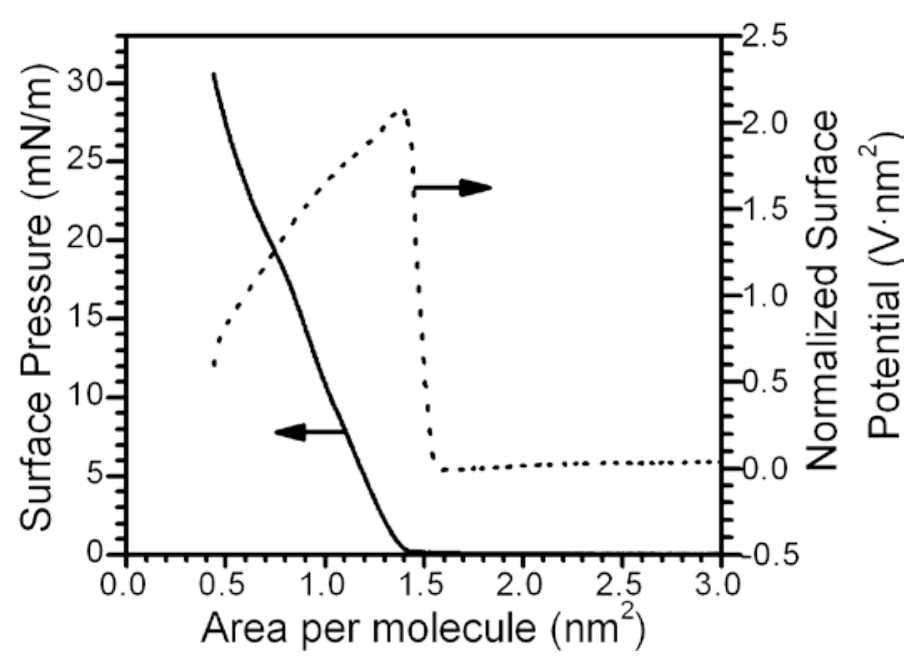

Figure 2. Surface pressure and normalized surface potential versus area per molecule isotherms of oxyZnPc onto water at $20^{\circ} \mathrm{C}$.

With the purpose of analysing in more detail the information provided by the $\pi$ - $A$ isotherm, the Young modulus, $K_{s}$, has been determined:

$$
\mathrm{K}_{\mathrm{S}}=-\mathrm{A} \cdot\left(\frac{\partial \pi}{\partial \mathrm{A}}\right)_{\mathrm{T}}
$$

By analysing the $K_{s}-\pi$ curves, phase transitions can be detected in terms of changes in the slope. Furthermore, $K_{s}$, provides information about the phases and phase transitions of the monolayer according to the classification of Davies and Rideal [29]. Figure 3 shows the $K_{s}-\pi$ curve for the oxyZnPc monolayer at the air-water interface with an indication of the phases and phase transitions according to the above mentioned criterion. 


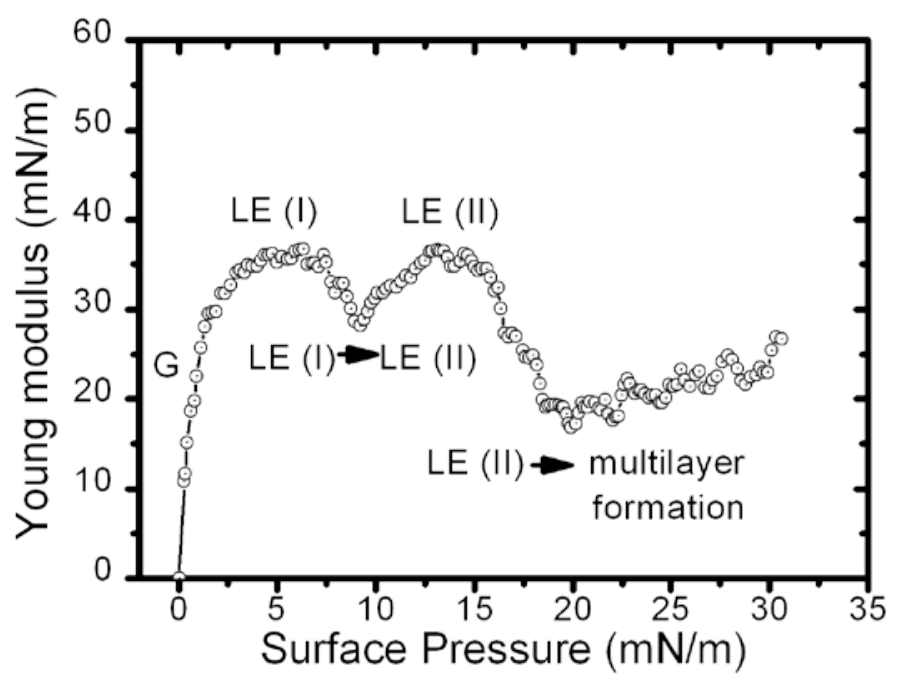

Figure 3. Young Modulus vs. surface pressure where the different phases and phase transitions of the oxyZnPc monolayer have been indicated. $\mathrm{G}$ denotes the gas phase and LE the liquid expanded phase.

The $\pi-A$ isotherm (Figure 2) for the oxyZnPc Langmuir monolayer shows the take-off at ca. $1.45 \mathrm{~nm}^{2}$ and the extrapolated area from the initial linear part of the isotherm is ca. $1.35 \mathrm{~nm}^{2}$. This value is significantly lower than the molecular area of oxyZnPc in a flat position $\left(2.3 \mathrm{~nm}^{2}\right.$ [1]), which is probably indicating that oxyZnPc molecules are already in a tilted orientation at the take-off and that there is a certain degree of aggregation within the molecules in the film. From simple geometrical considerations, taking $1.35 \mathrm{~nm}^{2}$ as the projected area of the Pc macrocycle of size $1.52 \mathrm{~nm}\left(2.3 \mathrm{~nm}^{2}\right)$, a tilt angle of around $36^{\circ}$ is obtained, that is lower than the one reported previously for other $\mathrm{ZnPc}[19,20]$ of around $50-60^{\circ}$, but closer to the most proposed nearly perpendicular orientation of the macrocycle plane with respect to the surface. The $\Delta V_{n}-A$ isotherm can often provide useful information relating to the molecular order within the monolayer, showing phase changes at slightly higher areas per molecule before they are detected in the $\pi-A$ isotherm, and this can be clearly seen in the case of oxyZnPc films (Figure 2) for which the take-off in the $\Delta V_{n}-A$ isotherm takes place at ca. $1.55 \mathrm{~nm}^{2}$. The sharp change in 
the surface potential in the $1.55-1.40 \mathrm{~nm}^{2}$ region could be indicative of a sudden reorientation of oxyZnPc molecules at the air-water interface upon the $\mathrm{G} \rightarrow \mathrm{LE}(\mathrm{I})$ transition. After the take-off in the $\pi$-A isotherm, $K_{s}$ values gradually increase with the surface pressure (Figure 3 ) showing values consistent with a liquid expanded phase, LE(I) accordingly to the Davies and Rideal classification [29]. A slope change in the $\pi-A$ isotherm occurs at approximately $9 \mathrm{mN} / \mathrm{m}$ after which the monolayer enters in another liquid expanded phase, LE(II). Two regions with similar negative slopes can be observed in the $\Delta V_{n}-A$ isotherm which are again consistent with two different liquid expanded regions. At $19 \mathrm{mN} / \mathrm{m}$ another slope change is evident in the $\pi-A$ isotherm accompanied by a decrease in the surface potential isotherm as well as a minimum in $K_{s}$ values followed by a slight increase in the Young modulus upon compression. Although these data may be suggesting the formation of a multilayered film at the air water interface, BAM images (Figure 4) and UV-Vis Reflection spectroscopy (Figure 5) have been used to provide further insight into the nature of the transition occurring at $19 \mathrm{mN} / \mathrm{m}$, since no agreement exists in literature for similar phthalocyanine systems.

At a surface pressure of $0 \mathrm{mN} / \mathrm{m}$, before the take-off in the $\pi$ - $A$ isotherm, the Langmuir film features many islands or domains of different sizes (Figure 4) which rapidly coalesce forming a uniform film that covers the whole water surface even at low surface pressures. This coalescence is also consistent with the sudden increase in the surface potential. This island formation was also observed by Peñacorada et al. [30] but in that case the islands were more rigid and no good coalescence was observed, probably due to the presence of a sulphonic group that provides a strong hydrophilic character to the molecule. The presence of these domains at $\pi=0 \mathrm{mN} / \mathrm{m}$ is indicative of the aggregation tendency of these molecules. Some authors [19] have indicated that for zinc phthalocyanines this aggregation tendency is lower than for copper phthalocyanines due to the ability of zinc to coordinate with water molecules. At higher surface 
pressures BAM images show a similar aspect until a surface pressure of ca. $20 \mathrm{mN} / \mathrm{m}$ at which the appearance of stripes suggests the formation of multilayers which are even more evident at a surface pressure of $27 \mathrm{mN} / \mathrm{m}$ at which the different brightness of the stripes is indicative of a disordered collapse of the Langmuir film. Normalized Reflection spectra, $\Delta R_{n}\left(\Delta R_{n}=\Delta R \cdot A\right)$, recorded upon the compression process are shown in Figure 5a. A decrease in the intensity of the spectra with increasing surface pressures is observed in the $0-19 \mathrm{mN} / \mathrm{m}$ region, which is indicative of a gradual decrease of the angle formed by the normal to the surface and the dipole transition moment of the oxyZnPc molecules. However, this tendency changes at a surface pressure of $19 \mathrm{mN} / \mathrm{m}$ after which an increase in the normalized reflection spectra with surface pressure occurs. This observation is consistent with the effective path length of the incident light corresponding to a multilayered film. Taken together these results are indicative of a multilayer formation at ca. $19 \mathrm{mN} / \mathrm{m}$. A comparison of these results and those presented by Qiu et al. [24] concludes that a similar value for the isotherm take-off is observed in both cases. However, in the paper of Qiu et al. an inflection point in the $\pi$-A isotherm at ca. $20 \mathrm{mN} / \mathrm{m}$ was observed and was attributed to an aggregation process. In contrast, the results foregoing mentioned in this contribution together with additional experimental evidences that will be shown in the next sections of this paper indicate that this inflection point is consistent with a multilayer formation process. Some differences can be observed in the Reflection spectra compared with those of Qiu et al. [24]. As the technique used to transfer the Langmuir films is different in both works, it seems that, due to the commented characteristics of the oxyZnPc Langmuir films, the transferred films in the horizontal (LS) and vertical (LB) mode present some differences. 

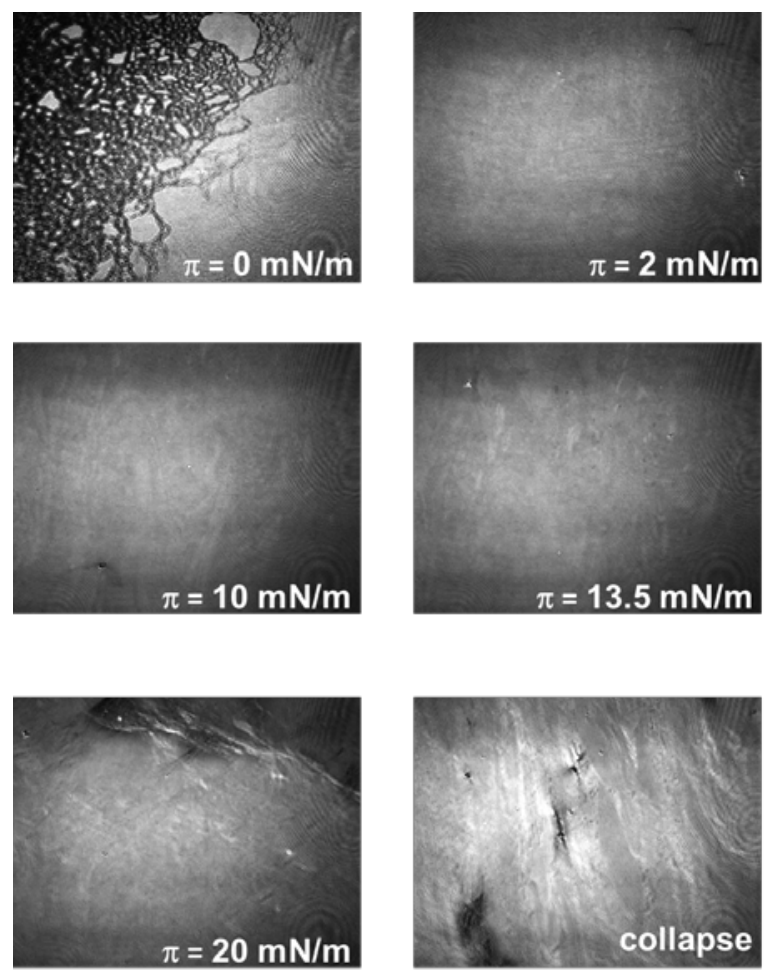

Figure 4. BAM images at the indicated surface pressures upon the compression process and image of a collapsed film. Images have a size of $3600 \mu \mathrm{m}$ x $4100 \mu \mathrm{m}$.

Reflection spectroscopy is a useful method for the in situ characterization of the monolayer at the air-interface. In addition, molecular orientation and aggregation can be investigated more directly by spectroscopic methods than is achievable using the classic monolayer techniques described above. A comparison of the UV-Vis spectra of oxyZnPc at the air-water interface upon the compression process with respect to the oxyZnPc UV-Vis spectrum in solution (Figure 5.b) shows a very significant change in the relative intensities of the bands which is attributable to orientational effects in the film. In addition, the Q band (680 $\mathrm{nm}$ in solution) is much broader in the films suggesting aggregation effects, in agreement with the results of Qiu et al. [24]. 

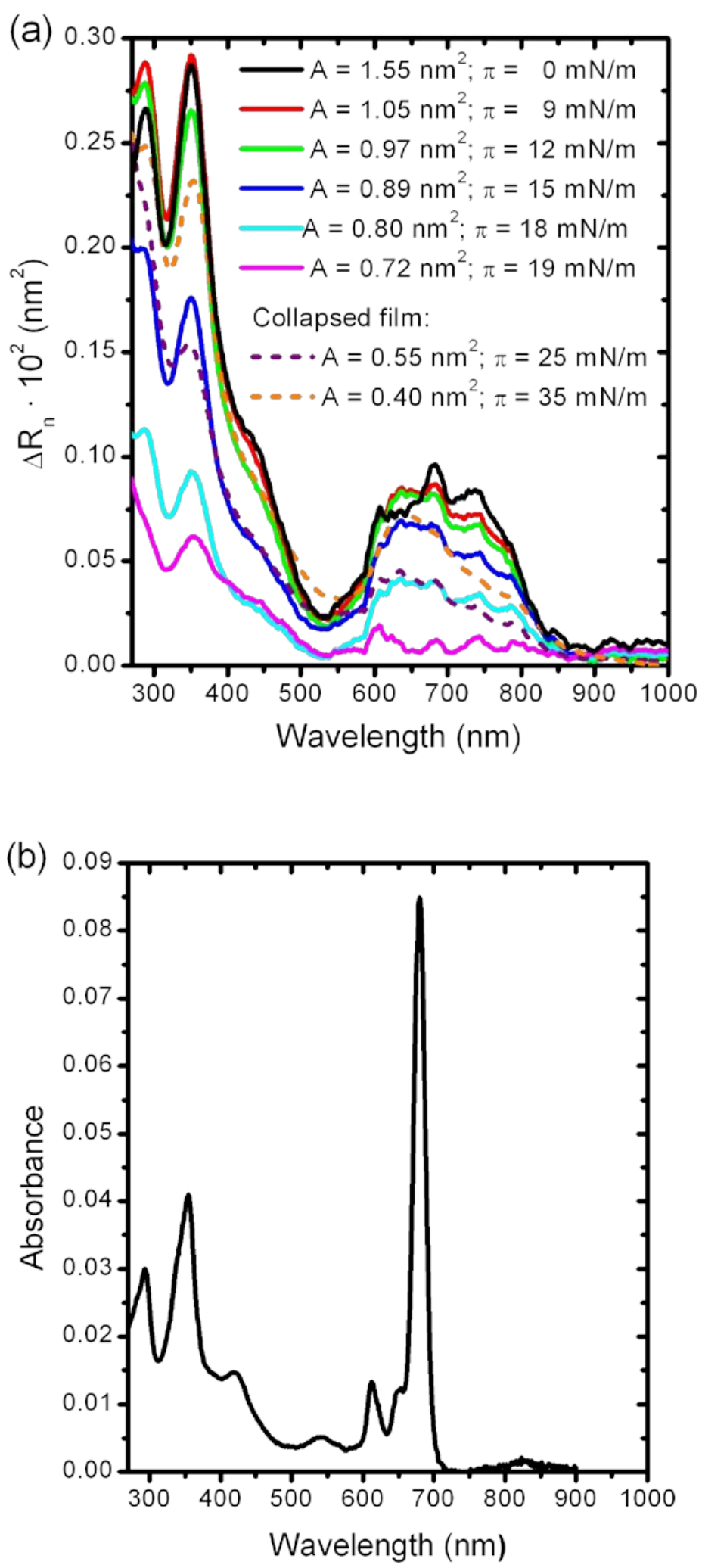

Figure 5. (a) Normalized UV-Vis Reflection spectra of oxyZnPc Langmuir films recorded upon the compression process at the indicated areas per molecule and surface pressures. (b) Spectrum of oxyZnPc in a $5 \cdot 10^{-6} \mathrm{M} \mathrm{CHCl}_{3}$ solution. 


\subsection{Langmuir-Blodgett films}

Langmuir monolayers were transferred onto solid substrates at a surface pressure of 15 $\mathrm{mN} / \mathrm{m}$ by the vertical dipping method showing a transfer ratio of 1 with a $\mathrm{Y}$ deposition type. The deposition process was also investigated using a QCM. Thus, the frequency change $(\Delta f)$ for a QCM quartz resonator before and after the deposition process was determined. The deposited mass was obtained taking into account the Sauerbrey equation:

$$
\Delta f=-\frac{2 \cdot f_{0}^{2} \cdot \Delta m}{A \cdot \rho_{q}^{1 / 2} \cdot \mu_{q}^{1 / 2}}
$$

where $f_{0}$ is the fundamental resonant frequency of $5 \mathrm{MHz}, \Delta m(\mathrm{~g})$ is the mass change, $A$ is the electrode area, $\rho_{q}$ is the density of the quartz $\left(2.65 \mathrm{~g} / \mathrm{cm}^{3}\right)$, and $\mu_{q}$ is the shear module $\left(2.95 \cdot 10^{11}\right.$ dyn $/ \mathrm{cm}^{2}$ ). Taking into account the Sauerbrey equation and the oxyZnPc molecular weight $(\mathrm{M}=1603.64 \mathrm{~g} / \mathrm{mol})$, the surface coverage $\Gamma(\Gamma=\Delta m / A \cdot M)$ has been obtained. In Figure 6 the surface coverage vs. the number of layers has been plotted. The values of $\Gamma$ are consistent with the transfer of one monolayer in each transfer step. The nearly linear relationship between $\Gamma$ and the number of layers implies that the transference is reproducible, i.e. a constant amount of oxyZnPc is transferred and the molecular environment of the molecules in each layer is practically constant upon the deposition process for 6 consecutive layers. Further deposition processes yield deviations from this linear relationship which is indicative of a poorer transfer ratio and loss of quality in the multilayered film. 


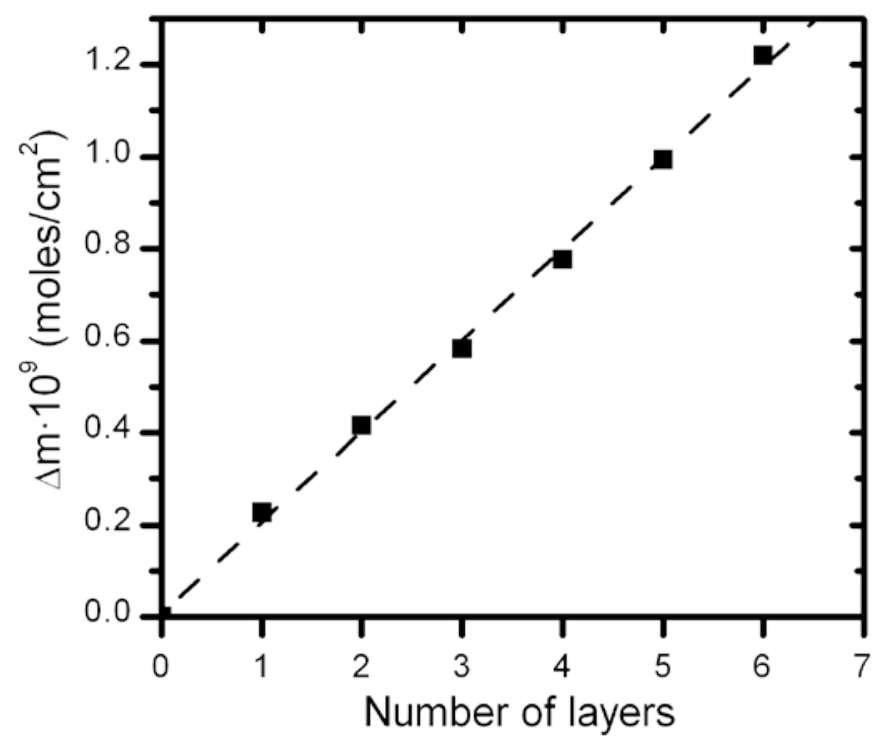

Figure 6. Dependence of the film surface coverage, $\Gamma$, with the number of transferred layers at $15 \mathrm{mN} / \mathrm{m}$.

AFM images of LB films transferred at several surface pressures during the withdrawal of the substrate are shown in Figure 7. The section analysis of Figure 7.a (film transferred at a surface pressure of $10 \mathrm{mN} / \mathrm{m}$ ), shown in Figure 7.e, shows mainly the presence of a monolayer with a thickness of 1.2-1.3 nm. Considering the ring plane as a nearly square section of $1.52 \mathrm{~nm}$ side [1], it can be concluded that the ring plane is oriented with a tilt angle of $38-31^{\circ}$ with respect to the normal to the surface. This value is in good agreement with the tilt angle calculated from the $\pi$ - $A$ isotherm as indicated before. However, the section analysis also shows the presence of regions with a higher film thickness which is indicative of the presence of other orientations. Figure 7.b (film transferred at a surface pressure of $15 \mathrm{mN} / \mathrm{m}$ ) shows a more uniform film and the section analysis shows a film thickness between 1.2 and $1.5 \mathrm{~nm}$ for the monolayer, but other regions with a higher film thickness are also evident. The section analysis of Figure 7.c (film transferred at a surface pressure of $20 \mathrm{mN} / \mathrm{m}$ ), shown in Figure 7.f, shows a film thickness of $2.6 \mathrm{~nm}$ and even higher in some regions, indicating the presence of a multilayered LB film. Finally, Figure 7.d corresponds to a drop-cast film that shows a film 
thickness of $2.5 \mathrm{~nm}$, consistent with the spontaneous formation of a bilayer. The similarity between the LB film images transferred at surface pressures higher than $19 \mathrm{mN} / \mathrm{m}$ and the cast film images represents another confirmation of a multilayer formation at $19 \mathrm{mN} / \mathrm{m}$.

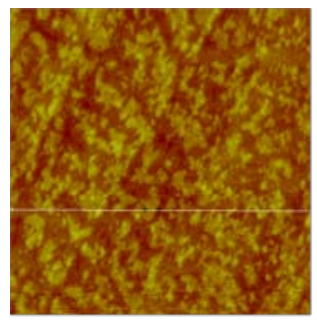

(a)

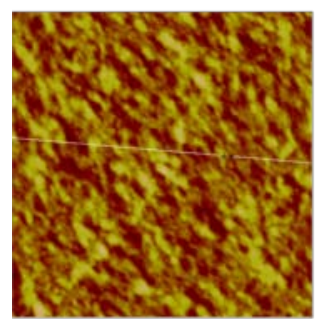

(c)

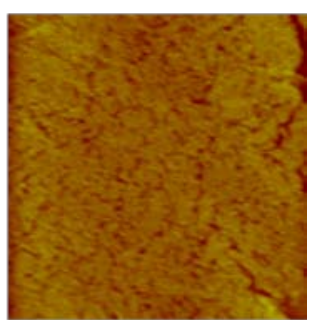

(b)

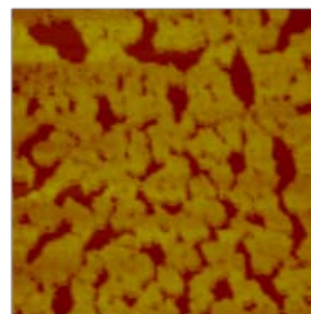

(d)

(e)
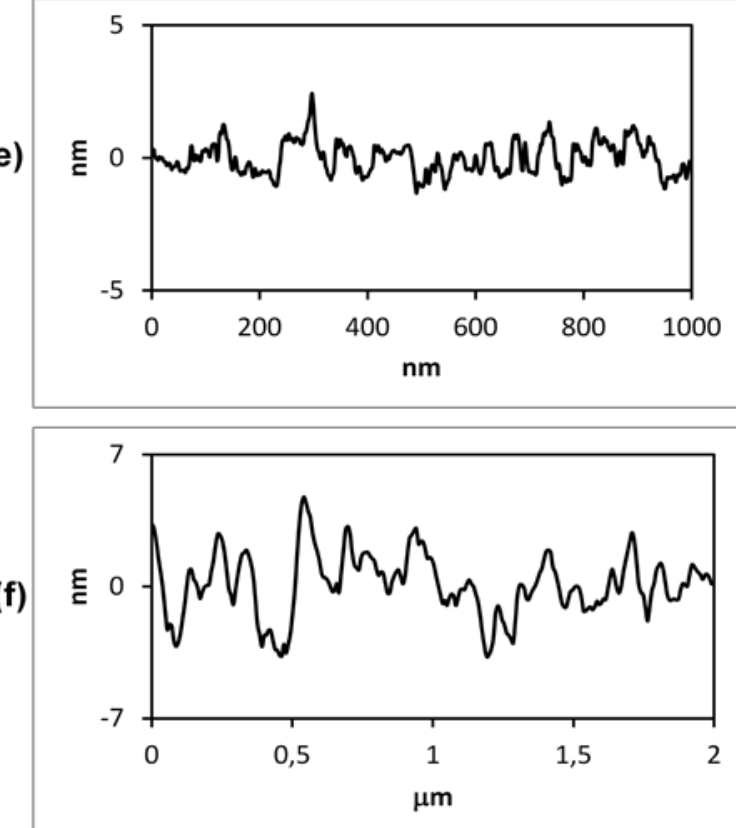

Figure 7. AFM images of LB films of oxyZnPc deposited onto a HOPG substrate at a surface pressure of transference: (a) $10 \mathrm{mN} / \mathrm{m}$, (b) $15 \mathrm{mN} / \mathrm{m}$, (c) $20 \mathrm{mN} / \mathrm{m}$, and (d) of a drop-cast film. (a) and (b) size $1 \mu \mathrm{m}$ x $1 \mu \mathrm{m}$, (c) and (d) size $2 \mu \mathrm{m}$ x $2 \mu \mathrm{m}$. Vertical colour bar from 0 to $10 \mathrm{~nm}$. (e) Section of the AFM image 7.a, and (f) Section of the AFM image 7.c. 
The comparison of the UV-Vis spectrum in solution (Figure 5.b) with those of the Langmuir films (Figure 5.a) and of the LB film (Figure 8) shows very significant differences, with a notable reduction in the intensity of the Q band for the film spectra (observed also in previous works with Pc [25, 31-33]). These observations are indicative of a rather different orientation and aggregation of the molecules in the films. Redisolution of oxyZnPc LB films in chloroform yields an identical spectrum to that of the pristine compound dissolved in this solvent, which clearly indicates that no reactions upon the film fabrication process occur, i.e., the changes in the spectra are only attributable to changes in the chemical environment of the molecule or formation of aggregates but not to rupture or formation of chemical bonds. In addition, this result indicates that the aggregation is reversible. Moreover, the spectrum of the LB film is similar to that of the Langmuir film, indicating that during the transfer process the structure or organization of the film is preserved. In addition, no shift in the band position (wavelength of 293 and $355 \mathrm{~nm}$ for the Shore band, $425 \mathrm{~nm}$ for the $\mathrm{n}-\pi^{*}$ transition, 613 and 680 nm for the Q band) of the solution spectrum with respect to Langmuir or LB films spectra can be observed. The Q band for Langmuir and LB films shows a relative increase of the sub-bands of aggregates both at lower and higher wavelengths with respect to that of the monomer $(\lambda=680$ $\mathrm{nm}$ ), indicating a major degree of aggregation in the LB films than in solution. A similar UVVis spectrum to that of the LB film is observed for a cast film (Figure 8), that indicates similarities in their molecular organization (molecular interactions). In addition, the bandwidth at half height of the Q band is narrower for the LB film, indicating a higher degree of order for the LB film. 


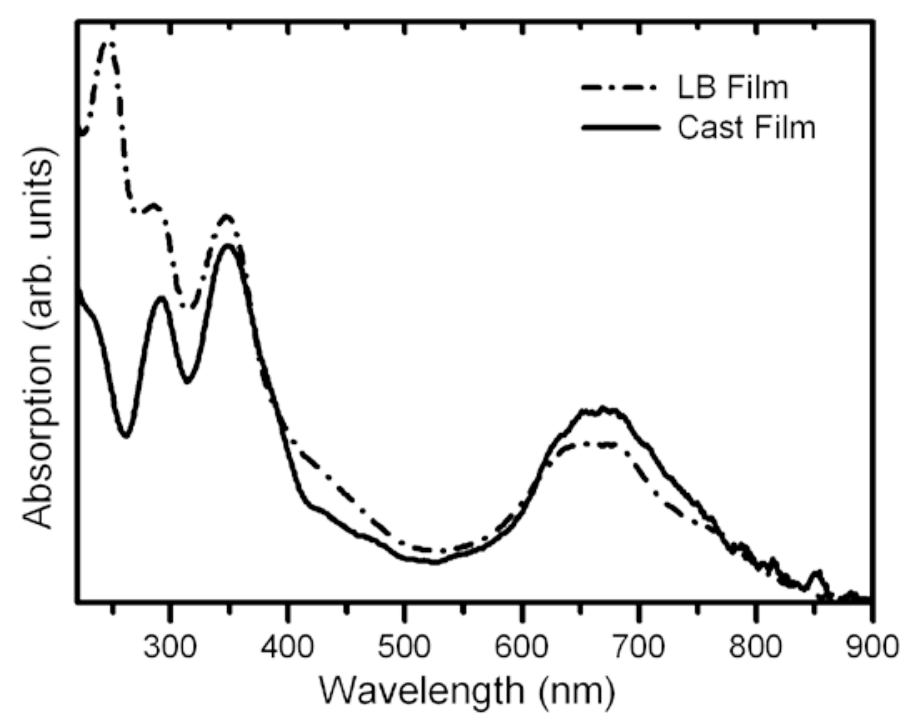

Figure 8. UV-Vis spectra of oxyZnPc LB (transferred at $15 \mathrm{mN} / \mathrm{m}$ ) and cast films.

Figure 9 shows the IR spectrum of a $\mathrm{KBr}$ pellet of oxyZnPc as well as the IR spectrum of an LB film of oxyZnPc.Table 1 gathers the vibrational mode assignments of the main bands based on previously published data of similar compounds [9, 19, 22, 34, 35]. The relative intensities of the bands change from the $\mathrm{KBr}$ pellet to the $\mathrm{LB}$ film which is attributable to orientational effects in the film. Souto et al. [22] attributed the differences in the IR spectra between the pellet and the LB film to an edge-on orientation, which in our case is in agreement with the AFM results discussed above. In addition, the bandwidth in the 900-1600 $\mathrm{cm}^{-1}$ region is larger for the LB film, probably due to a higher chromophore density, which may cause an overlap of multiple bands with slightly shifted frequencies [36]. The slight shift of the $\mathrm{CH}_{2}$ stretching bands (at 2922 and $2853 \mathrm{~cm}^{-1}$ for the LB film and 2920 and $2850 \mathrm{~cm}^{-1}$ for the pellet) are indicative of a slight less crystalline or ordered state in the LB film with respect to the pellet. 


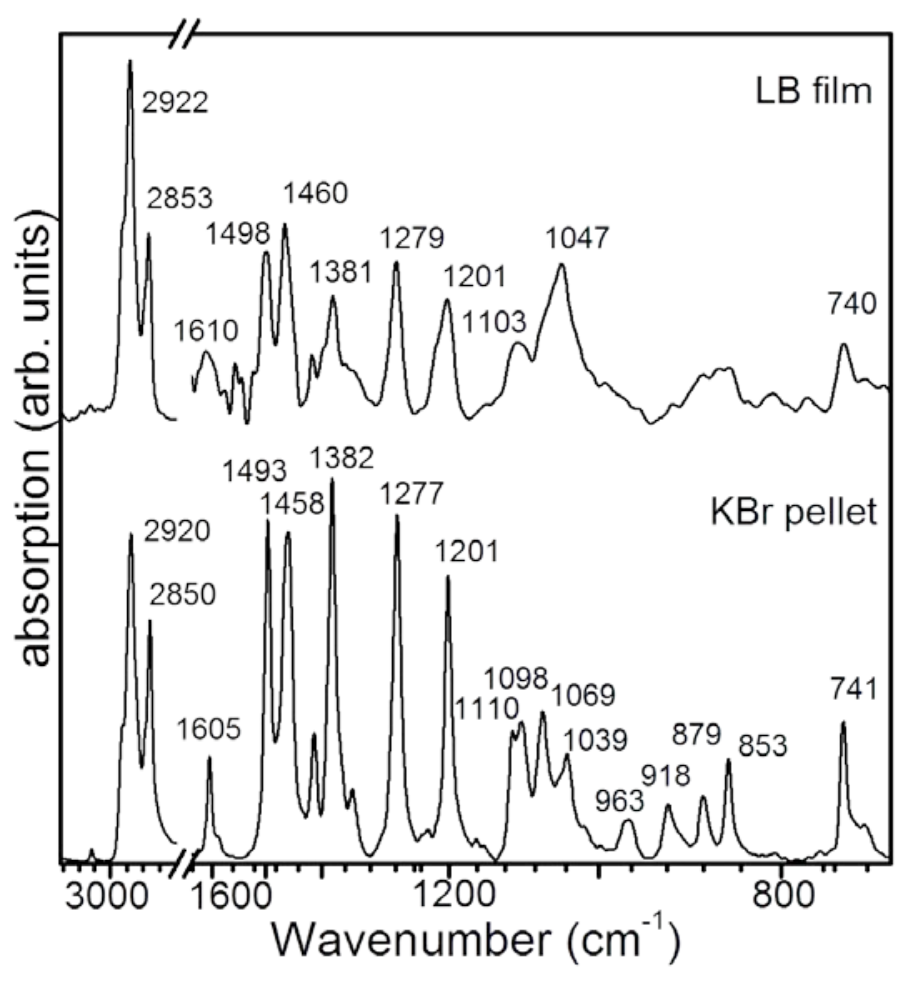

Figure 9. IR spectra of oxyZnPc incorporated in a LB film and in a $\mathrm{KBr}$ pellet. 
Table 1. Band positions and assignments for IR spectra of oxyZnPc in $\mathrm{LB}$ films and in $\mathrm{KBr}$ pellet.

\begin{tabular}{|c|c|c|}
\hline band position $\left(\mathrm{cm}^{-1}\right)$ & band position $\left(\mathrm{cm}^{-1}\right)$ & Assignment \\
\hline LB film & \multicolumn{2}{|l|}{ KBr pellet } \\
\hline 2922 (strong) & 2920 (strong) & $\mathrm{CH}_{2}$ stretch antisymmetric \\
\hline 2853 (medium) & 2850 (medium) & $\mathrm{CH}_{2}$ stretch symmetric \\
\hline 1610 (weak) & 1605 (medium) & Phenyl ring stretch \\
\hline 1498 (medium) & 1493 (strong) & Pyrrole stretch \\
\hline 1460 (medium) & 1458 (strong) & $\mathrm{CH}_{2}$ scissoring in chain \\
\hline \multirow[t]{2}{*}{1381 (medium) } & \multirow[t]{2}{*}{1382 (strong) } & $\mathrm{C}-\mathrm{H}$ bending in $\mathrm{CH}_{3}$ \\
\hline & & Isoindole stretch \\
\hline \multirow[t]{2}{*}{1279 (medium) } & \multirow[t]{2}{*}{1277 (strong) } & C-H bending \\
\hline & & (Pc)Ar-O-C stretch \\
\hline 1201 (medium) & 1201 (strong) & Ar-O-C stretch \\
\hline 1103 (medium) & 1110 (medium) & $\begin{array}{l}\mathrm{CH}_{2}-\mathrm{CH}_{2} \text { stretch in chain, } \\
\text { in chain direction }+\mathrm{CH} \text { in } \\
\text { plane bending }\end{array}$ \\
\hline - (weak, unresolved) & 1098 (medium) & $\mathrm{C}-\mathrm{H}$ bending in $\mathrm{Pc}$ \\
\hline 1047 (medium) & 1069 (medium) & $\mathrm{CH}$ in plane bending \\
\hline - (weak, unresolved) & 1039 (medium) & Ar-O-C stretch \\
\hline - (weak, unresolved) & 963 (weak) & Benzene breath \\
\hline - (weak, unresolved) & 918 (weak) & C-H bending \\
\hline - (weak, unresolved) & 879 (weak) & C-C-C bend \\
\hline - (weak, unresolved) & 853 (weak) & Pc ring stretch \\
\hline 740 (weak) & 741 (medium) & Pc ring stretch \\
\hline
\end{tabular}


Figure 10.a shows the cyclic voltammetric response, expressed as current density $(j)$ vs. potential $(E)$, of an upstroke LB film of oxyZnPc transferred on a GCE sheet. The open circuit potential (OCP) of a GCE-oxyZnPc monolayer in the $0.1 \mathrm{M} \mathrm{NaClO}_{4}$ electrolyte solution is $0.230 \mathrm{~V}$. The first scan towards anodic potentials in the $[-0.75 \mathrm{~V}, 1.2 \mathrm{~V}]$ potential range shows an oxidation peak, labelled as $\mathrm{O}_{1}$, together with two other weak weaves, one of reduction, labelled as $\mathrm{I}_{\mathrm{R}}$, and another of oxidation labelled as $\mathrm{I}_{\mathrm{O}}$. The first scan towards cathodic potentials in the $\left[-1.5 \mathrm{~V}, 0.2 \mathrm{~V}\right.$ ] potential range shows two weak reduction peaks, labelled as $\mathrm{R}_{1}$ and $\mathrm{R}_{2}$, together with an oxidation peak, labelled as $\mathrm{I}_{\mathrm{O}}$. This peak notation will be explained and discussed later. $\mathrm{R}_{1}$ and $\mathrm{R}_{2}$ peaks overlap with hydrogen evolution, which makes their observation rather difficult. The $\mathrm{O}_{1}$ oxidation peak and the $\mathrm{R}_{1}$ and $\mathrm{R}_{2}$ reduction peaks show an irreversible behaviour since their corresponding reduction and oxidation peaks can hardly be seen. After six cycles in the $[-1.5 \mathrm{~V}, 1.2 \mathrm{~V}]$ potential range the $\mathrm{R}_{1}$ and $\mathrm{R}_{2}$ reduction peaks are not observed and a new weak oxidation peak, $\mathrm{O}_{1}{ }_{1}$, appears. To complement the information provided by the cyclic voltammograms, differential pulse voltammetric experiments on the same experimental system were performed and the results are shown in Figure 10.b. $\mathrm{O}_{1}$ peak is the most significant in the first scan towards anodic potentials with a little pre-peak situated in the potential position corresponding to the O' 1 peak, and a new peak, $\mathrm{O}_{2}$, is observed. In the first scan towards cathodic potentials and the second scan towards anodic potentials, the peaks shown in Figure 10.a are also identified and their intensity is constant after repeated cycles, scanning either towards cathodic or anodic potentials in the [-1.5 V, $1.2 \mathrm{~V}]$ potential range. 

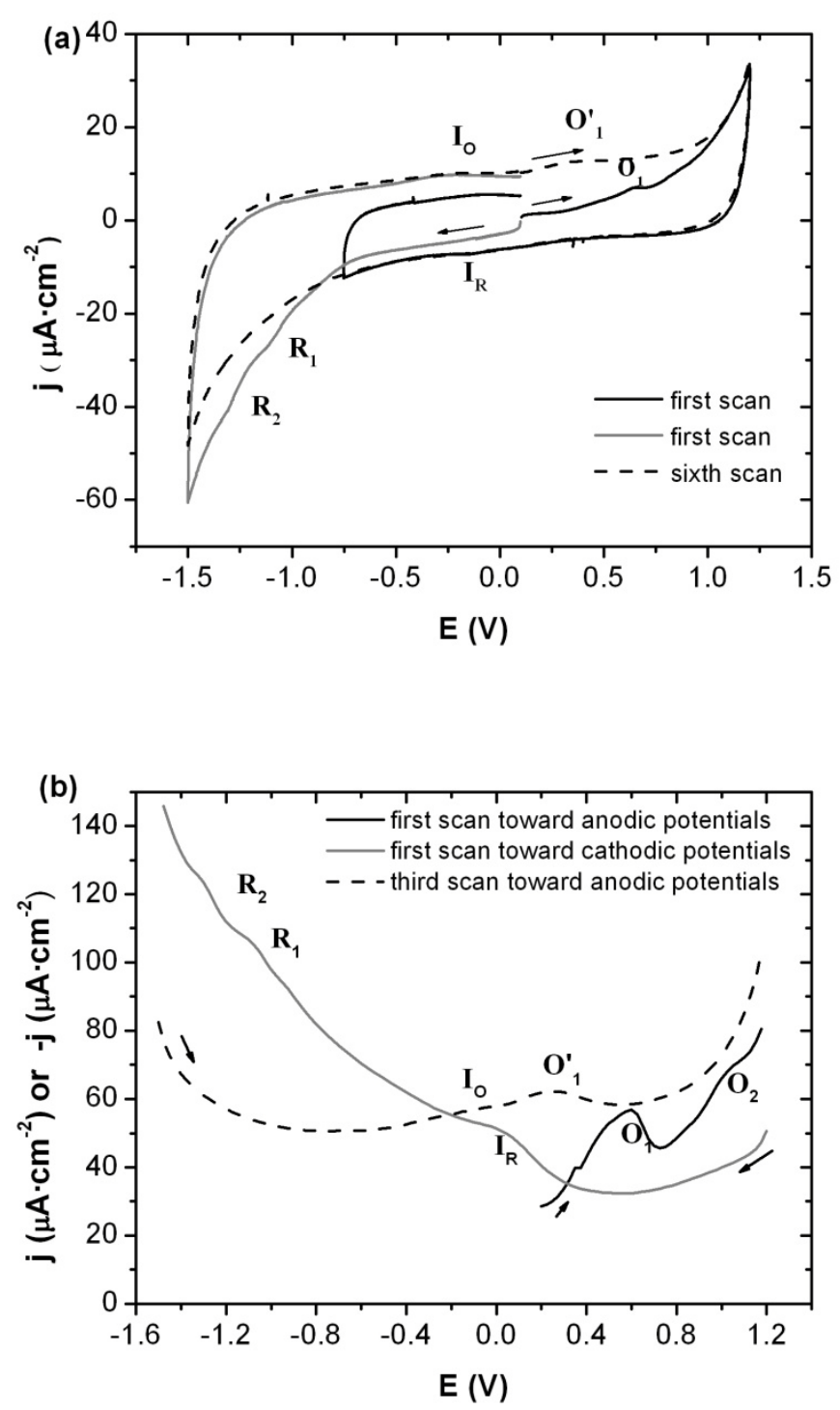

Figure 10. (a) Cyclic voltammograms at $50 \mathrm{mV} / \mathrm{s}$ and (b) Differential pulse voltammogram at $50 \mathrm{mV} / \mathrm{s}$, in a $0.1 \mathrm{M} \mathrm{NaClO}_{4}$ solution on a GCE sheet modified with an upstroke oxyZnPc LB film, deposited at a surface pressure of $10 \mathrm{mN} / \mathrm{m}$. Arrows indicate the direction of the scan.

In the next paragraph we will discuss the previous figures, comparing the peak potentials for the different redox processes observed in the voltammograms with the half-wave redox potentials reported in the literature for substituted $\mathrm{Zn}(\mathrm{II})$ phthalocyanines. It is well known that 
in the metallo-phthalocyanine complexes the oxidation state of the phthalocyanine ring is $\operatorname{Pc}(-$ 2), and that the redox processes in the case of zinc(II) phathalocyanines take place in the aromatic phthalocyanine ring [37]. The electrochemical behaviour of different peripherally substituted Zn(II) phthalocyanines has been studied in solution, either in dimethylformamide (DMF) $[14,16,38,39]$ or in dried benzonitrile [40]. In some of these studies, the half-wave redox potentials have been determined and the phthalocyanine ring couples involved in each reduction and oxidation processes have been assigned using spectroelectrochemical techniques. These results are summarized in Table 2 for octa and tetra substituted thiol-derivatised zinc(II) phthalocyanine complexes [16, 38], and tetra substituted \{2-[2-(1-naphthyloxy)ethoxy]ethoxy\} zinc(II) phthalocyanine complexes [39]. Using the same techniques, half-wave redox potentials of a substituted phthalocyanine with hexyloxy groups in non-peripheral positions and chlorinated phenyl groups in peripheral positions [40] have also been calculated in benzonitrile solution, and the results are also gathered in Table 2.

Table 2. Half-wave potentials of substituted Zn(II) phthalocyanines.

\begin{tabular}{|c|c|c|c|c|c|c|c|}
\hline \multicolumn{7}{|c|}{$\mathrm{E}_{1 / 2}(\mathrm{vs} \mathrm{Ag} / \mathrm{AgCl}(1 \mathrm{M}) / \mathrm{V}$} \\
\hline $\mathrm{O}_{1}$ & $\mathrm{O}_{2}$ & $\mathrm{R}_{1}$ & $\mathrm{R}_{2}$ & $\mathrm{R}_{3}$ & $\mathrm{R}_{4}$ & $\begin{array}{c}\text { Working } \\
\text { electrode }\end{array}$ & Reference \\
\hline $\mathrm{Pc}^{-2} / \mathrm{Pc}^{-1}$ & $\mathrm{Pc}^{-1} / \mathrm{Pc}^{0}$ & $\mathrm{Pc}^{-2} / \mathrm{Pc}^{-3}$ & $\mathrm{Pc}^{-3} / \mathrm{Pc}^{-4}$ & $\mathrm{Pc}^{-4} / \mathrm{Pc}^{-5}$ & $\mathrm{Pc}^{-5} / \mathrm{Pc}^{-6}$ & & \\
\hline 0.66 & & -0.87 & -1.31 & -1.86 & -2.26 & $\mathrm{GCE}$ & {$[16]$} \\
\hline 0.77 & & -0.66 & -1.03 & -1.55 & -1.71 & $\mathrm{GCE}$ & {$[16]$} \\
\hline 0.64 & & -0.81 & -1.16 & & & $\mathrm{GCE}$ & {$[16]$} \\
\hline 0.62 & & -0.9 & -1.33 & & & $\mathrm{GCE}$ & {$[38]$} \\
\hline 0.58 & & -1.15 & -1.40 & & & $\mathrm{Pt}$ & {$[39]$} \\
\hline 0.55 & 0.95 & & & & & $\mathrm{Pt}$ & {$[40]$} \\
\hline
\end{tabular}


Few articles have reported the electrochemical behaviour of $\mathrm{Zn}(\mathrm{II})$ phthalocyanines deposited on the surface of an electrode and immersed in aqueous electrolytes [16, 17]. Yoshimoto et al. [17] studied films of tetraphenyl substituted Zn(II) phthalocyanines adsorbed on an $\mathrm{Au}(111)$ single crystal electrode immersed in a $0.1 \mathrm{M} \mathrm{HClO}_{4}$ electrolyte solution. These authors obtained a reversible redox process with a reduction peak potential at $-0.100 \mathrm{~V}$ and an oxidation potential of $-0.090 \mathrm{~V}$ (vs. Ag/AgCl electrode). Scanning Tunnelling Microscopy (STM) results revealed that the high order in the ZnPc layer disappears when the applied potential is made more negative, but the ordered layer is formed again reversing the potential to more positive values. Therefore, it was concluded that the redox peak observed involves a structural change in the ZnPc layer.

Figure 11 shows the cyclic voltammograms of the oxyZnPc LB films transferred on GCE at two different surface pressures and following up and down-up stroke transfer processes. Two sets of curves are shown: the first voltammograms scanning towards anodic potentials in the $[-0.75 \mathrm{~V}, 1.2 \mathrm{~V}]$ range and the first voltammograms scanning towards cathodic potentials in the $[-1.5 \mathrm{~V}, 0.2 \mathrm{~V}]$ range. The oxidation and reduction peak potentials of the different processes shown in Figure 10 are also identified on all the curves in Figure 11 and are summarized in Table 3. A comparison of these values with the half-wave/formal potentials reported in Table 2 permits the identification of the $\mathrm{O}_{1}$ and $\mathrm{O}_{2}$ oxidation peaks with the $\mathrm{Pc}^{-2} / \mathrm{Pc}^{-1}$ and $\mathrm{Pc}^{-1} / \mathrm{Pc}^{0}$ redox processes, and the $\mathrm{R}_{1}$ and $\mathrm{R}_{2}$ reductions peaks with the $\mathrm{Pc}^{-2} / \mathrm{Pc}^{-3}$ and $\mathrm{Pc}^{-3} / \mathrm{Pc}^{-4}$ redox processes. Therefore, freshly deposited LB films incorporating oxyZnPc undertake redox processes on the surface of a GCE electrode in an aqueous electrolyte. 


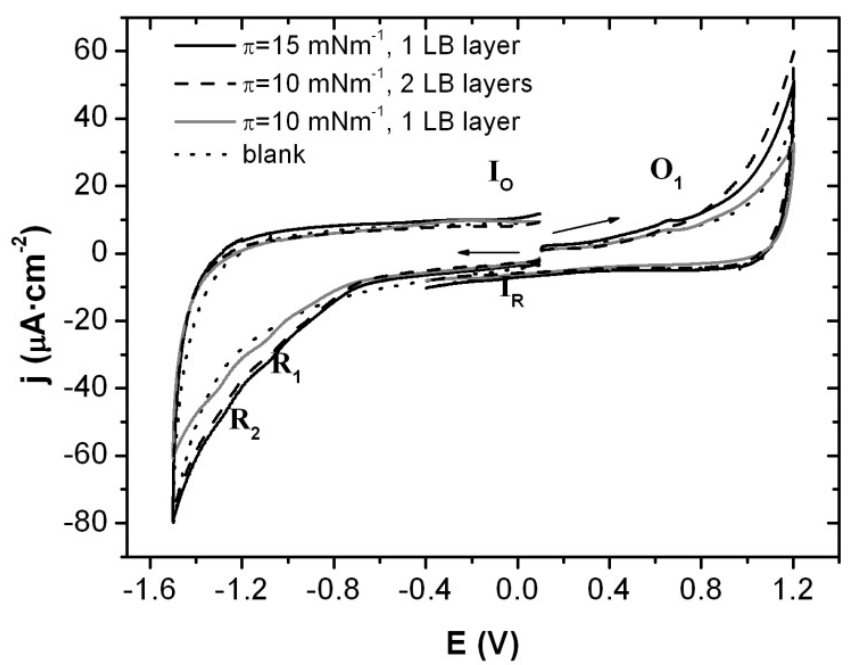

Figure 11. Cyclic voltammograms at $50 \mathrm{mV} / \mathrm{s}$ in a $\mathrm{NaClO}_{4}$ solution on a GCE sheet modified with: an upstroke LB film at a surface pressure of $10 \mathrm{mN} / \mathrm{m}$ (black lines); an upstroke LB film at a surface pressure of $15 \mathrm{mN} / \mathrm{m}$ (gray lines); an down-up stroke LB film at a surface pressure of $10 \mathrm{mN} / \mathrm{m}$ (dash lines). Arrows indicate the direction of the scan.

Table 3. Peak potentials of oxyZnPc and energy gap.

\begin{tabular}{|c|c|c|c|c|c|}
\hline oxyZnPc & \multicolumn{2}{|c|}{ oxidation } & \multicolumn{2}{|c|}{ reduction } & $\mathrm{E}_{\mathrm{p}}\left(\mathrm{O}_{1}\right)-\mathrm{Ep}\left(\mathrm{R}_{1}\right) / \mathrm{eV}$ \\
\hline & $\mathrm{E}_{\mathrm{p}}\left(\mathrm{O}_{1}\right) / \mathrm{V}$ & $\mathrm{E}_{\mathrm{p}}\left(\mathrm{O}_{2}\right) / \mathrm{V}$ & $\operatorname{Ep}\left(R_{1}\right) / V$ & $\operatorname{Ep}\left(R_{2}\right) / V$ & \\
\hline $\begin{array}{c}\text { upstroke } 1 \\
\text { layer LB film } \\
\pi=10 \mathrm{mN} / \mathrm{m}\end{array}$ & 0.665 & 0.857 & -1.106 & -1.309 & $\begin{array}{c}1.771 \\
700\end{array}$ \\
\hline $\begin{array}{l}\text { Down-up } \\
\text { stroke } 2 \text { layer } \\
\text { LB film } \\
\pi=10 \mathrm{mN} / \mathrm{m}\end{array}$ & 0.650 & - & -1.070 & -1.293 & $\begin{array}{c}1.720 \\
720\end{array}$ \\
\hline $\begin{array}{l}\text { upstroke } 1 \\
\text { layer LB film } \\
\pi=15 \mathrm{mN} / \mathrm{m}\end{array}$ & 0.650 & - & -1.106 & -1.309 & $\begin{array}{c}1.756 \\
705\end{array}$ \\
\hline $\begin{array}{l}\text { Cast film } \\
5 \text { layers }\end{array}$ & 0.593 & - & -0.970 & -1.392 & $\begin{array}{c}1.563 \\
790\end{array}$ \\
\hline Redox process & $\mathrm{Pc}^{-2} / \mathrm{Pc}^{-1}$ & $\mathrm{Pc}^{-1} / \mathrm{Pc}^{0}$ & $\mathrm{Pc}^{-2} / \mathrm{Pc}^{-3}$ & $\mathrm{Pc}^{-3} / \mathrm{Pc}^{-4}$ & \\
\hline
\end{tabular}


Figure 12.a shows the cyclic voltammograms of an oxyZnPc cast film deposited on the surface of a rod GCE. To prepare the cast film, $1 \mu \mathrm{L}$ of a $0.06 \mathrm{mg} / \mathrm{mL}$ oxyZnPc solution in chloroform was deposited on the surface of the electrode. From the electrode area and the molecular area of the oxyZnPc, a deposition of 5 layers of oxyZnPc is estimated under these experimental conditions. The OCP of the GCE-oxyZnPc layer in the $0.1 \mathrm{M} \mathrm{NaClO}_{4}$ electrolyte solution is $0.110 \mathrm{~V}$. An oxidation peak, labelled as $\mathrm{O}_{1}$, and two reduction peaks, labelled as $\mathrm{R}_{1}$ and $\mathrm{R}_{2}$, can be seen on the voltammograms exhibiting a quasi-reversible behaviour, being $\mathrm{R}_{\mathrm{O}}$ and $\mathrm{O}_{\mathrm{R}}$ the corresponding reduction and oxidation peaks. Under repeated cycles, the $\mathrm{O}_{1}$ peak becomes flatter and the intensity of the reduction peaks decreases. In order to discriminate the non-faradaic background current of the voltammograms shown in Figures 11 and 12.a, the capacitive current of the blank experiment (background current) was subtracted [41], and the resulting curves are shown in Figure 12.b. This is a rough approximation to faradaic current but it can be used to compare qualitatively the behaviour of the oxyZnPC films. The oxidation and reduction peaks and waves in Figure 12.b have been labelled according to the curves shown in Figures 10.b and 12.a. The $\mathrm{O}_{1}$ oxidation peak and the $\mathrm{R}_{1}$ and $\mathrm{R}_{2}$ reduction peaks for the cast film correspond with those of the LB films. In addition, cast films are characterized by a broader $\mathrm{O}_{1}$ peak.

The first oxidation peak potential values for the $\mathrm{Pc}^{-2} / \mathrm{Pc}^{-1}$ process are slightly shifted to more negative values (Table 3) as the surface pressure of the LB layer or the number of layers deposited on the surface increase. According to the AFM images shown in Figure 7, this phenomenon is consistent with the increase in the molecular aggregation or the presence of different orientations of the oxyZnPc molecules on the surface. The second oxidation process, $\mathrm{Pc}^{-1} / \mathrm{Pc}^{0}$ (only clearly seen on Figure 10.b), can be distinguished in LB monolayers transferred at $\pi=10 \mathrm{mN} / \mathrm{m}$ and $15 \mathrm{mN} / \mathrm{m}$ indicating that the formation of the neutral Pc ring is favoured in ordered monolayers with a low aggregation, where the effect of the electrolyte can stabilise the 
increase of the positive charge on the surface $\left(\mathrm{ZnPc}^{2+}\right)$. The oxidation processes in $\mathrm{LB}$ films feature a significant irreversible character. This observation can be attributed to an irreversible aggregation or orientation of molecules after the oxidation process (structural change). The corresponding reduction peak of the $\mathrm{Pc}^{-2} / \mathrm{Pc}^{-1}$ couple appears at $E_{p}\left(R_{O}\right)=0.492 \mathrm{~V}$ for cast films, and in LB films is correlated with the wave $I_{R}$ in Figure 10.b that has been identified as a double wave in Figure 12.b at $E_{p}\left(I_{R}\right)=0 \pm 0.100 \mathrm{~V}$. After the first anodic scan, the $\mathrm{O}_{1}$ peak moves to the position of the O’ ${ }_{1}$ peak, $E_{p}\left(O^{\prime}{ }_{1}\right)=0.260 \pm 0.010 \mathrm{~V}$ (Figure 10). This phenomenon is observable for the three types of LB layers presented in this work, and is consistent with a change in the surface layer structure after the first oxidation process that remains with the subsequent cycles, either in the $[-0.75 \mathrm{~V}, 1.2 \mathrm{~V}]$ or in the $[-1.5 \mathrm{~V}, 1.2 \mathrm{~V}]$ potential range. In the case of LB films transferred at $\pi=10 \mathrm{mN} / \mathrm{m}$ and $15 \mathrm{mN} / \mathrm{m}$ a $\mathrm{I}_{O}$ peak, $E_{p}\left(I_{O}\right)=-0.076 \pm 0.40 \mathrm{~V}$, appears scanning towards positive potentials that precedes the $\mathrm{O}_{1}{ }_{1}$ oxidation peak. The $\mathrm{I}_{\mathrm{O}}$ and the wide $\mathrm{I}_{\mathrm{R}}$ peaks are attributable to a capacitive change on the surface originated by a process of adsorption/desorption or by a structural change of the LB layer. This molecular restructuration in the film takes place as a consequence of a potential variation on the electrode and precedes or follows the redox process of the $\mathrm{Pc}^{-2} / \mathrm{Pc}^{-1}$ couple [17].

The values of the $\mathrm{Pc}^{-2} / \mathrm{Pc}^{-3}$ and $\mathrm{Pc}^{-2} / \mathrm{Pc}^{-3}$ first reduction peak potentials in $\mathrm{LB}$ films depend on the number of layers deposited on the GCE surface (Table 3)while in cast films no well-defined peaks are obtained. This result further confirms that oxyZnPc molecules incorporated in LB films present a higher degree of order. After repeated cycles the reduction peaks become less visible on the voltammograms indicating an increase of irreversibility in the reduction process which might be due to the successive structural changes in the Pc layer.

Assuming that the oxyZnPc deposited on the GCE is an intrinsic semiconducting layer, the first oxidation and reduction potentials can be correlated with the HOMO and LUMO energy levels of the oxyZnPc, respectively [42]. Then, the value resulting of the expression 
$e_{o} \cdot\left(E_{O 1}^{o}-E_{R 1}^{o}\right)$, where $e_{o}$ is the electron charge and $E^{o}$ terms represent the standard potentials, corresponds to the energy gap between HOMO and LUMO energy levels. The values of the standard redox potentials of species confined on an electrode surface can be approximated by the values of peak potentials [43] and then, the values of $e_{o} \cdot\left(E_{p}\left(O_{1}\right)-E_{p}\left(R_{1}\right)\right.$ are shown in Table 3. Despite the approximated character of these values, when they are transformed in the corresponding wavelength, an acceptable agreement with the position of the Q band in the spectra is obtained. This agreement is more significant in the case of the LB monolayers. The reason for the discrepancies in the case of cast films or multi-layered LB films could be due to the fact that taking the peak potentials as the standard potentials is not a good approximation in the case of multilayers deposited on an electrode surface [44]. 

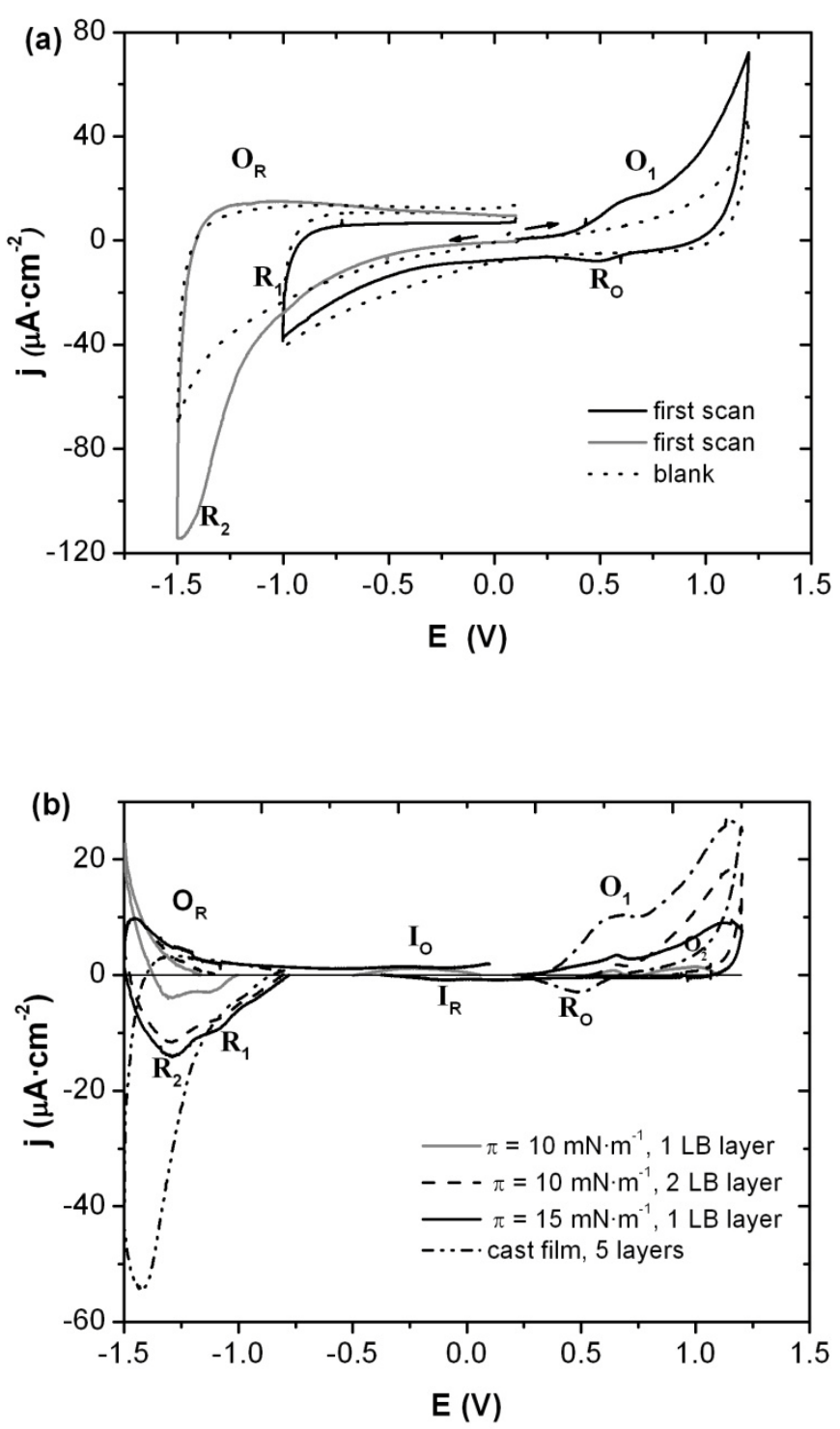

Figure 12. (a) Cyclic voltammograms at $50 \mathrm{mV} / \mathrm{s}$ in a $\mathrm{NaClO}_{4}$ solution on a GCE rod modified with a cast film of the oxyZnPc. Arrows indicate the direction of the scan. (b) Cyclic voltammograms of Figures 11 and 12.a after subtraction of the background current.

\section{Conclusions}

A zinc substituted phthalocyanine, namely octakis(oxyoctyl)phthalocyanine of zinc, oxyZnPc, has been assembled into mono and multilayered films by means of the Langmuir- 
Blodgett technique. Langmuir films were prepared at the air-water interface and characterized by surface pressure and surface potential vs. area per molecule isotherms and by Brewster angle microscopy, which reveal that this material can only form true monomolecular films at relatively low surface pressures since collapse occurs at ca. $19 \mathrm{mN} / \mathrm{m}$. AFM experiments revealed the formation of high quality LB films free of holes or three-dimensional defects at low surface pressures of transference. In addition, UV-Vis and IR experiments revealed orientational effects in the monolayer.

The electrochemical properties of the films were studied by means of cyclic voltammetry and differential pulse voltammetric experiments. The LB films of oxyZnPc show redox response on a GCE. From the analysis of the redox peaks in LB films, the gap between the HOMO and LUMO energy levels was estimated, and found that there is a good agreement between this value and the position of the Q band in the film spectra.

Future investigations will be devoted to improve the transfer of larger number of layers with the LB technique, and to investigate the behaviour of these films for organic FET or organic solar cells.

\section{Acknowledgements}

The authors are grateful for financial assistance of Ministerio de Economia $y$ Competitividad and Ministerio de Ciencia e Innovación from Spain and fondos FEDER in the framework of projects CTQ2012-33198 and SAF2011-30216-C02-01, respectively. I.G. acknowledges his DGA pre-doctoral grant. 


\section{References}

[1] S.M. O’Flaherty, L. Wiegart, O. Konovalov, B. Struth, Langmuir 21 (2005) 11161.

[2] G. de la Torre, C.G. Claessens, T. Torres, Chem. Comm. 20 (2007) 2000.

[3] D. Schlettwein, Chapter 10, and T. Nyokong, Chapter 7, in J.H. Zagal, F. Bedioui, J-P. Dodelet, N N$_{4}$-Macrocyclic Metal Complexes, Springer, N.Y., 2006.

[4] Q. Wang, W.M. Campbell, E.E. Bonfantani, K.W. Jolley, D.L. Officer, P.J. Walsh, K. Gordon, R. Humphry-Baker, M.K. Nazeeruddin, M. Grätzel, J. Phys. Chem. B 109 (2005) 15397.

[5] L. Valli, Adv. Colloid Interf. Sci. 116 (2005) 13.

[6] V. Gadenne, M. Bayo-Bangoura, L. Porte, L. Patrone, J. Colloid Interf. Sci.359 (2011) 47.

[7] C. Schünemann, C. Elschner, A.A. Levin, M. Levichkova, K. Leo, M. Riede, Thin Solid Films 519 (2011) 3939.

[8] H. Peisert, I. Biswas, M. Knupfer, T. Chassé, Phys. Status Solidi B 246 (2009) 1529.

[9] L. Gaffo, V. Zucolotto, M.R. Cordeiro, W.C. Moreira, O.N. Oliveira Jr., F. Cerdeira, M.J.S.P. Brasil, Thin Solid Films 515 (2007) 7307.

[10] A. Grofcsik, P. Baranyai, I. Bitter, V. Csokai, M. Kubinyi, K. Szegletes, J. Tatai, T. Vidóczy, J. Mol. Struct. 704 (2004) 11.

[11] C. Hadjur, G. Wagnières, F. Ihringer, Ph. Monnier, H. van der Bergh, J. Photochem. Photobiol. B 38 (1997) 196.

[12] N. Kawashima, N. Nakajima, Progress Org. Coat. 72 (2011) 34.

[13] J. Tu, T. Wang, W. Shi, G. Wu, X. Tian, Y. Wang, D. Ge, L. Ren, Biomaterials 33 (2012) 7903.

[14] B. Schöllhorn, J.P. Germain, A. Pauly, C. Maleysson, J.P. Blanc, Thin Solid Films 326 (1998) 245. 
[15] J.P. Germain, A. Pauly, C. Maleysson, J.P. Blanc, B. Schöllhorn, Thin Solid Films 333 (1998) 235.

[16] K.I. Ozoemena, T. Nyokong, Microchem. J. 75 (2003) 241.

[17] S. Yoshimoto, E. Tsutsumi, K. Suto, Y. Honda, K. Itaya, Chem. Phys. 319 (2005) 147.

[18] A. Chowdbury, B. Biswas, M. Majumder, M. Kumas Sanyal, B. Mallik, Thin Solid Films $520(2012) 6695$.

[19] E.J. Osburn, L-K. Chau, S-Y. Chen, N. Collins, D.F. O’Brien, N.R. Armstrong, Langmuir 12 (1996) 4784.

[20] S. Fouriaux, F. Armand, O. Araspin, A. Ruaudel-Teixier, E.M. Maya, P. Vazquez, T. Torres, J. Phys. Chem. 100 (1996) 16984.

[21] M.J. Cook, A.J. Dunn, M.F. Daniel, R.C.O. Hart, R.M. Richardson, S.J. Roser, Thin Solid Films 159 (1988) 395.

[22] J. Souto, Y. Gorbunova, M.L. Rodríguez-Méndez, S. Kudrevich, J.E. van Lier, J.A. de Saja, J. Raman Spectroscopy 27 (1996) 649.

[23] M. Kimura, H. Ueki, K. Ohta, H. Shirai, N. Kobayashi, Langmuir 22 (2006) 5051.

[24] Y. Qiu, P. Chen, M. Liu, Langmuir 24 (2008) 7200.

[25] L-C. Chen, C-C. Wang, C-B. Cheng, Thin Solid Films 517 (2009) 1790.

[26] P. Cea, S. Martín, A. Villares, D. Möbius, M.C. López, J. Phys. Chem. B 110 (2006) 963.

[27] P. Cea, J.P. Morand, J.S. Urieta, M.C. López, F.M. Royo, Langmuir 12 (1996) 1541.

[28] S. Martín, P. Cea, C. Lafuente, F.M. Royo, M.C. López, Surface Science 563 (2004) 27.

[29] J.T. Davies, E.K. Rideal, Interfacial phenomena, Academic Press, NY 1993.

[30] F. Peñacorada, J. Souto, J.A. de Saja, L. Brehmer, Appl. Surf. Sci. 246 (2005) 425.

[31] Q. Liu, H. Liu, Y. Bian, X. Wang, Y. Chen, J. Jiang, X. Li, J. Colloid Interf. Sci. 300 (2006) 298.

[32] A. Sivanesan, S. Abraham John, J. Electroanal. Chem. 634 (2009) 64. 
[33] W.J. Schutte, M. Sluyters-Rehbach, J.H. Sluyters, J. Phys. Chem. 97 (1993) 6069.

[34] T. Del Caño, R. Aroca, J.A. De Saja, M.L. Rodríguez-Méndez, Langmuir 19 (2003) 3747.

[35] K. Lewandowska, D. Wrobel, A. Biadasz, R. Swietlik, J. Photochem. Photobiol. A 200 (2008) 225.

[36] M. Haro, B. Giner, I. Gascon, F.M. Royo, M.C. López, Macromolecules 40 (2007) 2058.

[37] The Porphyrin Handbook. Volume 16. Phthalocyanines: Spectroscopic and electrochemical characterization. Edited by K. M. Kadhis, K.M. Smith, R. Guilard. Academic Press, San Diego (California) 2003.

[38] B. Agboola, K. I. Ozoemena, T. Nyokong, Electrochim. Acta 51 (2006) 4379-4387.

[39] I. Acar, Z. Biyikloglu, A. Koca, H. Kanteki, Polyhedron 29 (2010) 1475-1484.

[40] S. Y. Al-Rag, M. Messali, S. Al-Refae, B.S. Ghanem, Z. Moussa, S. Ahmed, M. E. ElKhouly, S. Fukuzumi, Dyes and Pigments 9 (2011) 231-236.

[41] L. J. C. Jeuken and F. A. Armstrong, J. Phys. Chem. B 105 (2001) 5271-5282.

[42] Handbook of Porphirin Science: with applications to chemistry, physics, materials science, engineering, biology and medicine, Vol 3. Editors: K.M. Kadish, K.M. Smith, R. Guillard World Scientific Publishing, London (2010).

[43] A. J. Bard and L. R. Faulkner, Electrochemical methods. Fundamentals and applications, John Wiley\& Sonds, NY (2001).

[44] E. Laviron, J. Electroanal. Chem. 112 (1980) 11. 


\section{Figure Captions}

Figure 1. Chemical structure of Zinc 2,3,9,10,16,17,23,24-octakis(octyloxy)-29H,31Hphthalocyanine, abbreviated as oxyZnPc in this contribution.

Figure 2. Surface pressure and normalized surface potential versus area per molecule isotherms of oxyZnPc onto water at $20^{\circ} \mathrm{C}$.

Figure 3. Young Modulus vs. surface pressure where the different phases and phase transitions of the oxyZnPc monolayer have been indicated. $\mathrm{G}$ denotes the gas phase and LE the liquid expanded phase.

Figure 4. BAM images at the indicated surface pressures upon the compression process and image of a collapsed film. Images have a size of $3600 \mu \mathrm{m}$ x $4100 \mu \mathrm{m}$.

Figure 5. (a) Normalized UV-Vis Reflection spectra of oxyZnPc Langmuir films recorded upon the compression process at the indicated areas per molecule and surface pressures. (b) Spectrum of oxyZnPc in a $5 \cdot 10^{-6} \mathrm{M} \mathrm{CHCl}_{3}$ solution.

Figure 6. Dependence of the film surface coverage, $\Gamma$, with the number of transferred layers at $15 \mathrm{mN} / \mathrm{m}$.

Figure 7. AFM images of LB films of oxyZnPc deposited onto a HOPG substrate at a surface pressure of transference: (a) $10 \mathrm{mN} / \mathrm{m}$, (b) $15 \mathrm{mN} / \mathrm{m}$, (c) $20 \mathrm{mN} / \mathrm{m}$, and (d) of a drop-cast film. (a) and (b) size $1 \mu \mathrm{m} \times 1 \mu \mathrm{m}$, (c) and (d) size $2 \mu \mathrm{m}$ x $2 \mu \mathrm{m}$. Vertical colour bar from 0 to $10 \mathrm{~nm}$.

(e) Section of the AFM image 7.a, and (f) Section of the AFM image 7.c.

Figure 8. UV-Vis spectra of oxyZnPc LB (transferred at $15 \mathrm{mN} / \mathrm{m}$ ) and cast films.

Figure 9. IR spectra of oxyZnPc incorporated in a LB film and in a $\mathrm{KBr}$ pellet. 
Figure 10. (a) Cyclic voltammograms at $50 \mathrm{mV} / \mathrm{s}$ and (b) Differential pulse voltammogram at $50 \mathrm{mV} / \mathrm{s}$, in a $0.1 \mathrm{M} \mathrm{NaClO}_{4}$ solution on a GCE sheet modified with an upstroke oxyZnPc LB film, deposited at a surface pressure of $10 \mathrm{mN} / \mathrm{m}$. Arrows indicate the direction of the scan.

Figure 11. Cyclic voltammograms at $50 \mathrm{mV} / \mathrm{s}$ in a $\mathrm{NaClO}_{4}$ solution on a GCE sheet modified with: an upstroke LB film at a surface pressure of $10 \mathrm{mN} / \mathrm{m}$ (black lines); an upstroke LB film at a surface pressure of $15 \mathrm{mN} / \mathrm{m}$ (gray lines); an down-up stroke LB film at a surface pressure of $10 \mathrm{mN} / \mathrm{m}$ (dash lines). Arrows indicate the direction of the scan.

Figure 12. (a) Cyclic voltammograms at $50 \mathrm{mV} / \mathrm{s}$ in a $\mathrm{NaClO}_{4}$ solution on a GCE rod modified with a cast film of oxyZnPc. Arrows indicate the direction of the scan. (b) Cyclic voltammograms of Figures 11 and 12.a after subtraction of the background current. 


\section{Table captions}

Table 1. Band positions and assignments for IR spectra of oxyZnPc in LB films and in $\mathrm{KBr}$ pellet.

Table 2. Half-wave potentials of substituted Zn(II) phthalocyanines.

Table 3. Peak potentials of oxyZnPc and energy gap. 